\title{
Human donor milk for the vulnerable infant: a Canadian perspective
}

\author{
Julia Panczuk ${ }^{1,2}$, Sharon Unger ${ }^{3,4}$, Deborah O'Connor ${ }^{5,6}$ and Shoo K Lee $3,4,7^{*}$
}

\begin{abstract}
Breast milk is the normal way to feed infants and is accepted worldwide as the optimal first source of nutrition. Though the majority intend to breastfeed, many mothers of sick, hospitalized newborns, particularly those of very low birth weight, are unable to provide a full volume of milk due to numerous physical and emotional barriers to breastfeeding. This vulnerable population of infants may benefit most from receiving breast milk nutrition and thus pasteurized donor milk should be the first consideration for supplementation when there is an inadequate supply of mother's own milk. This commentary will briefly review the history of milk banking in Canada, as well as the best available evidence for donor milk use in the very low birth weight population, including available economic analyses, with a view to advocate for its use in these vulnerable infants.
\end{abstract}

Keywords: Breast milk, Mother's own milk, Pasteurized human donor milk, Very low birth weight infants

\section{Background}

Breast milk is the normal way to feed infants and is accepted worldwide as the optimal exclusive first source of nutrition [1-5]. The overwhelming majority of Canadian mothers wish to breastfeed. For mothers of vulnerable infants, however, particularly those of very low birth weight (VLBW, $<1500 \mathrm{~g}$ ) or requiring gastrointestinal surgery, it is more than simply a matter of desire. Despite their best intentions, only a minority can produce a full volume of milk due to numerous physical and emotional barriers to breastfeeding, including maternal illness, stress, immature lactocytes, and separation from their infant. In our neonatal intensive care unit (NICU), the largest in Canada, only $30 \%$ of mothers are able to achieve exclusive breastfeeding. Until very recently, preterm formula was offered in most Canadian NICUs as a standard supplement in the absence of mother's own milk. It is in this vulnerable population of infants, however, that the benefits of breast milk may be most important. Our first priority must be to support mothers in the provision of their own milk and our second priority should be to have donor milk routinely available as a safe, efficacious and cost-effective

\footnotetext{
* Correspondence: sklee@mtsinai.on.ca

${ }^{3}$ Department of Paediatrics, University of Toronto, Toronto, ON, Canada ${ }^{4}$ Department of Paediatrics, Mount Sinai Hospital, 600 University Avenue, Toronto, ON M5G 1X5, Canada

Full list of author information is available at the end of the article
}

supplement when it is not possible to give mother's own milk [6].

\section{Discussion}

The Canadian Paediatric Society and the American Academy of Pediatrics have recommended fortified breast milk as first-line nutrition for preterm and other high-risk infants since the mid to late 1990s $[7,8]$. The benefits of breast milk compared with formula in VLBW infants are well established. Preterm infants fed breast milk display improved feeding tolerance [9], develop fewer severe infections $[10,11]$ and fewer episodes of necrotizing enterocolitis (NEC) [12], are less colonized by pathogenic organisms $[13,14]$, and experience decreased lengths of hospital stay [15] and reduced rates of hospital re-admission after discharge [16]. Importantly, breast milk-fed preterm infants also have improved neurodevelopmental outcomes. A meta-analysis by Anderson et al. showed a significant increase in measures of cognitive function among breastfed infants compared with their formula-fed counterparts [17]. The effect of breast milk was greatest for LBW infants, and held true after adjusting for possible socioeconomic confounders. A recent large-scale observational study by Vohr et al. assessing early nutrition of extremely LBW infants found a dose-dependent response to breast milk exposure on cognitive outcome as assessed by the Bayley Mental Developmental Index at 18 months of age [18]; this effect 
persisted at 30 months [16]. The mechanism for improved cognitive outcomes is likely multifactorial: breast milk promotes optimal feeding tolerance, provides an optimum substrate for brain and somatic growth, and provides protection against many complications associated with preterm birth that may negatively impact neurodevelopment $[9-12,15]$.

The first human milk bank opened in Vienna, Austria in 1909 and the first in North America opened in 1919 in Boston, USA $[19,20]$. Banks continued to be established until the emergence of the HIV epidemic in the mid 1980s when many closed their doors in response to uncertainty of disease transmission via donor milk. With advances in donor screening and infectious disease testing assuring its safety, as well as mounting evidence for the benefit of breast milk in general, interest and demand has increased exponentially for donor milk.
Currently there are 13 non-profit donor milk banks in North America. In addition to a long-standing bank in Vancouver, Canada now has a second operational bank in Calgary, a third in Ontario (see Figure 1), and one in development in Quebec [20]. In Canada, donor milk has been advocated for by the Canadian Paediatric Society [6]. It is regulated by Health Canada under food guidelines and all banks follow donor screening protocols established by the Canadian Blood Services. Donor milk has been widely accepted as shown by the example in Ontario, Canada's largest province, where all tertiary care NICUs began importing donor milk within 6 months of the opening of the provincial milk bank. All Canadian banks are members of the Human Milk Banking Association of North America (HMBANA), whose policies guide the processing of human milk. The amount of milk dispensed by HMBANA banks rose from 409,077 ounces in

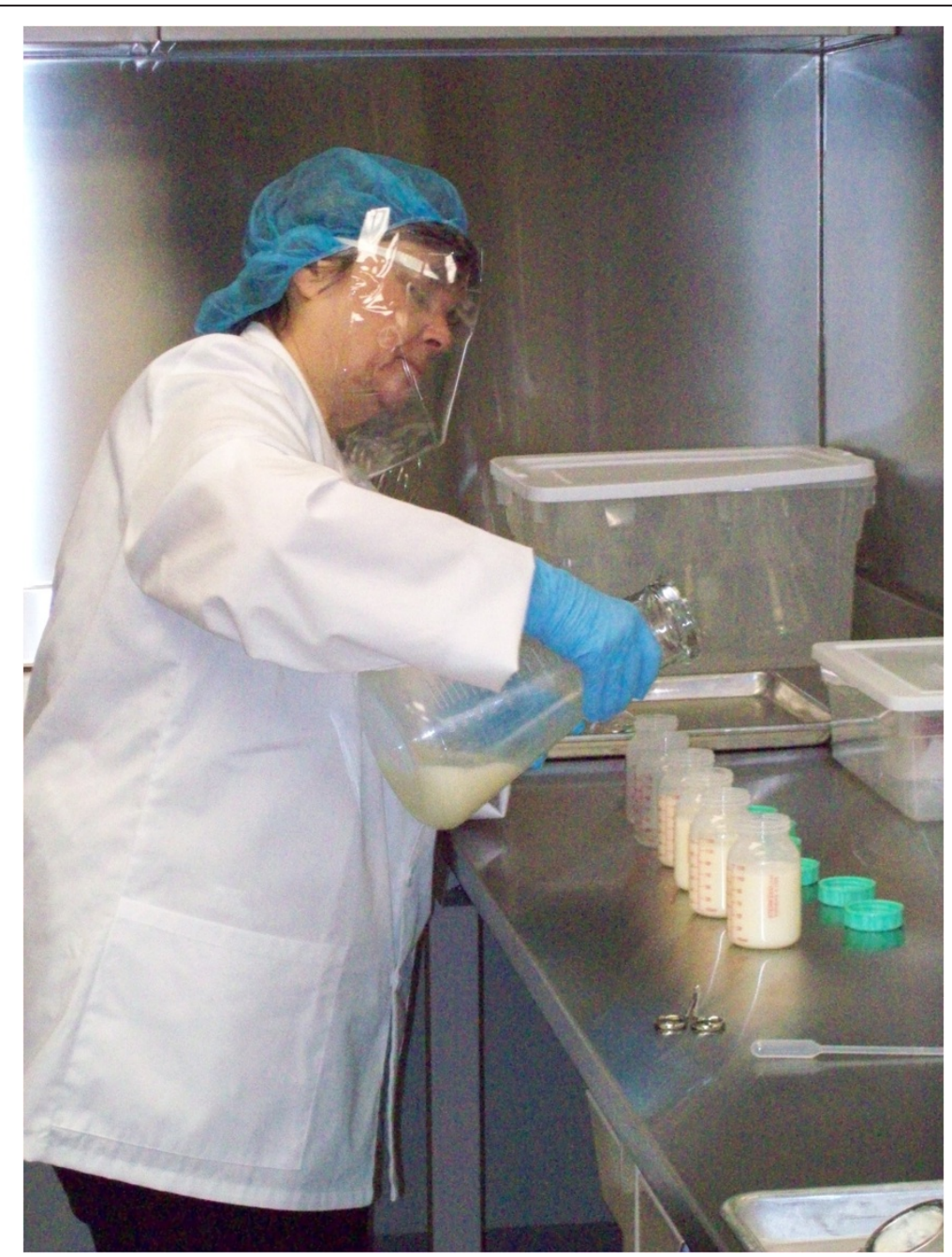

Figure 1 Processing donor milk at the Rogers Hixon Ontario Human Milk Bank. Donor milk is collected from across Ontario, Canada, processed, and redistributed through the Rogers Hixon Ontario Human Milk Bank. The milk bank dispensed 18,000 ounces of milk in the first 8 months since it opened. 
2000 to over 2 million ounces in 2011, a greater than $400 \%$ increase [20].

In North America, donor milk is pasteurized according to the Holder technique (see Figure 2) which, in combination with at least one additional container change and freeze/thaw cycle, can affect nutrient composition. This issue can be addressed by nutrient fortification of milk as required. However, pasteurization is known to have a greater impact on some of the bioactive components in milk [21]. For this reason, the efficacy of donor milk must be considered separately from mother's own milk when reviewing the literature. The majority of donor milk research was generated prior to 1985 when many milk banks closed. The best evidence for its efficacy is a Cochrane review by Quigley et al. [22]. This meta-analysis included 8 randomized controlled trials that compared formula feeding versus human donor milk in preterm infants and found higher rates of diarrhea and feeding intolerance among formula-fed infants, and more importantly, significantly higher rates of NEC. The review did not show an effect on long-term growth or development, although those infants fed formula displayed higher short-term rates of growth. The latter finding is not unexpected, as only one trial used nutrient-fortified donor milk-a practice that is now standard $[7,8]$. All but one trial were also over 20 years old, conducted at a time when morbidity and mortality for VLBW infants were far greater and feeding practices did not reflect preferential use of breast milk.

It is reasonable to expect that if similar trials were conducted today, infants fed fortified donor milk would not only experience improved growth, but many of the other beneficial effects of breast milk as well. One recent

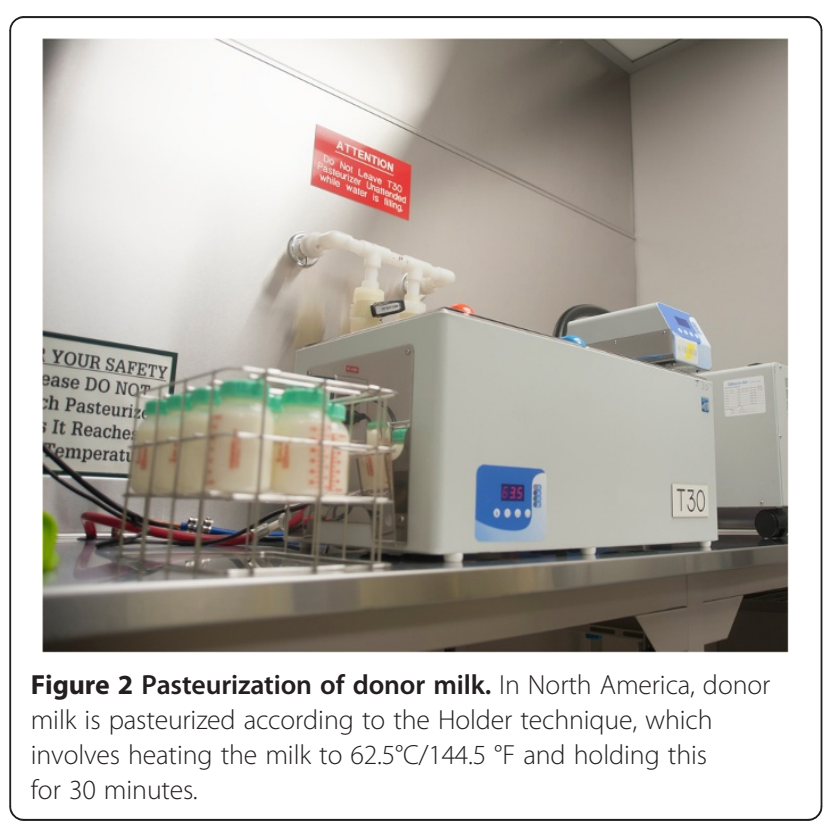

industry-sponsored trial demonstrated that an exclusively human milk-based diet, including human milk-based human milk fortifier (HMF) and donor milk, resulted in a significant reduction in medical and surgical NEC in extremely preterm infants compared with those supplemented with bovine-based products [23]. At present, there are two multi-centre randomized control trials underway whose aim is to assess the impact of receiving donor breast milk as compared with preterm formula when mother's milk is not available for very low birth weight infants: the American Milk Trial [24] and the Canadian Donor Milk for Improved Neurodevelopmental Outcomes Trial [25]. These are both large-scale trials, reflective of current era feeding practices in the most vulnerable infants, and have a primary outcome of long-term neurodevelopment as assessed by the Bayley Scales of Infant Development at 18 months corrected age.

There are also financial considerations in the use of donor breast milk. Operating a milk bank, including donor testing as well as processing, testing, and shipping donor milk entails a cost. However, in comparison with the cost of medical or surgical management of even one case of NEC or a resulting case of short bowel syndrome, this cost is nominal. Though there have been no Canadian analyses of the potential economic impact of donor milk, a Californian study estimated a cost savings to the healthcare system of $\$ 11$ for every $\$ 1$ spent on donor milk as a result of the reduction in hospital stay, NEC and sepsis associated with its use [26]. A recent study evaluating the cost-effectiveness of a $100 \%$ human milk-based diet including human milk-based fortifier for extremely preterm infants compared with bovine-based fortifier estimated a net savings of 3.9 NICU days and $\$ 8,167.17$ per infant in preventable costs for NEC [27].

\section{Conclusion}

Optimizing nutrition for preterm infants is of critical importance in promoting their health and improving their long term neurodevelopmental outcome. We must therefore advocate for improved supports enabling mothers to provide their own milk for their infant, as well as advocate for donor milk banking as the superior alternative in the absence of mother's own milk.

\section{Abbreviations}

HMBANA: Human Milk Banking Association of North America; HMF: Human milk fortifier; NEC: Necrotizing enterocolitis; NICU: Neonatal intensive care unit; (V)LBW: (Very) low birth weight.

\section{Competing interests}

The authors declare that they have no competing interests. No specific sources of funding were used in the writing of this article.

\section{Authors' contributions}

SU, JP and DOC conducted the literature review, JP wrote the manuscript, and SKL provided senior authorship and draft revision. All authors read and 
revised the manuscript critically for important intellectual content and approved the final manuscript.

\section{Authors' information}

JP is Clinical Fellow Neonatology, Department of Medicine, University of Toronto. SU is Staff Neonatologist, Department of Paediatrics, Mount Sinai Hospital and Assistant Professor, Department of Paediatrics, University of Toronto. DO is Professor, Department of Nutritional Sciences, University of Toronto and Senior Associate Scientist, Research Institute, The Hospital for Sick Children. SKL is Paediatrician-in-Chief, Mount Sinai Hospital and Professor, Departments of Paediatrics and Obstetrics and Gynaecology, University of Toronto.

\section{Acknowledgements}

No funding was received for this paper.

\section{Author details}

${ }^{1}$ Department of Medicine, University of Toronto, Toronto, ON, Canada. ${ }^{2}$ Division of Neonatology, The Hospital for Sick Children, 555 University Avenue, Toronto, ON M5G 1X8, Canada. ${ }^{3}$ Department of Paediatrics, University of Toronto, Toronto, ON, Canada. ${ }^{4}$ Department of Paediatrics, Mount Sinai Hospital, 600 University Avenue, Toronto, ON M5G 1X5, Canada. ${ }^{5}$ Department of Nutritional Sciences, University of Toronto, Fitzgerald Building, 150 College Street, Toronto, ON M5S 3E2, Canada. ${ }^{6}$ Research Institute, The Hospital for Sick Children, Toronto, Canada. ${ }^{7}$ Department of Obstetrics and Gynaecology, University of Toronto, Toronto, ON, Canada.

Received: 8 January 2014 Accepted: 12 April 2014 Published: 17 April 2014

\section{References}

1. Boland MC: Canadian paediatric society, nutrition committee: exclusive breastfeeding should continue to six months. Paediatr Child Health 2005, 10:148.

2. Infant Feeding Joint Working Group: Nutrition for Healthy Term Infants: Recommendations from Birth to Six Months. In A joint statement of Health Canada, Canadian Paediatric Society, Dietitians of Canada, and Breastfeeding Committee for Canada. Ottawa: Health Canada; 2014. http://www.hc-sc.gc. ca/fn-an/nutrition/infant-nourisson/recom/index-eng.php.

3. American Academy of Pediatrics Section on Breastfeeding: Breastfeeding and the use of human milk. Pediatrics 2012, 129(3):e827-e841.

4. World Health Organization: Global strategy for infant and young child feeding - The optimal duration of exclusive breastfeeding. Geneva: World Health Organization; 2001. http://apps.who.int/gb/archive/pdf_files/WHA54/ea54id4.pdf.

5. World Health Organization: Promoting proper feeding for infants and young children. Geneva: World Health Organization; 2004. http://www.who.int/ nutrition/topics/infantfeeding/en/.

6. Kim JH, Unger S: Canadian paediatric society, nutrition and gastroenterology committee: human milk banking. Paediatr Child Health 2010, 15(9):595-598.

7. American Academy of Pediatrics: Committee on Nutrition: Pediatric Nutrition Handbook. Elk Grove Village, IL: American Academy of Pediatrics; 1998.

8. Nutrition Committee of the Canadian Paediatric Society: Nutrient needs and feeding of preterm infants. Can Med Assoc J 1995, 152:1765-1785.

9. Sisk PM, Lovelady CA, Gruber KJ, Dillard RG, O'Shea TM: Human milk consumption and full enteral feeding among infants who weight $<=1250$ grams. Pediatrics 2008, 121(6):e1528-e1533.

10. Hylander MA, Strobino DM, Dhanireddy R: Human milk feedings and infection among very low birth weight infants. Pediatrics 1998, 102:E38.

11. El-Mohandes AE, Picard MB, Simmens SJ, Keiser JF: Use of human milk in the intensive care nursery decreases the incidence of nosocomial sepsis. J Perinatol 1997, 17:130-134.

12. Narayanan I, Prakash K, Bala S, Verma RK, Gujral W: Partial supplementation with expressed breast-milk for prevention of infection in low-birth-weight infants. Lancet 1980, 2:561-563.

13. Lucas A, Cole TJ: Breast milk and neonatal necrotising enterocolitis. Lancet 1990, 336:1519-1523.

14. Yoshioka H, Iseki K, Fujita K: Development and differences of intestinal flora in the neonatal period in breast-fed and bottle-fed infants. Pediatrics 1983, 72:317-321.
15. Schanler RJ, Shulman RJ, Lau C: Feeding strategies for premature infants: Beneficial outcomes of feeding fortified human milk versus preterm formula. Pediatrics 1999, 103:1150-1157.

16. Vohr BR, Poindexter BB, Dusick AM, McKinley LT, Higgins RD, Langer JC, Poole WK: Persistent beneficial effects of breast milk ingested in the neonatal intensive care unit on outcomes of extremely low birth weight infants at 30 months of age. Pediatrics 2007, 120(4):e953-e959.

17. Anderson JW, Johnstone BM, Remley DT: Breast-feeding and cognitive development: a meta-analysis. Am J Clin Nutr 1999, 70:525-535.

18. Vohr BR, Piondexter BB, Dusick AM, McKinley LT, Wright LL, Langer JC, Poole KW: Beneficial effects of breast milk in the neonatal intensive care unit on the developmental outcome of extremely low birth weight infants at 18 months of age. Pediatrics 2006, 118:e115-e123.

19. Jones F: History of North American donor milk banking: One hundred years of progress. J Hum Lact 2003, 19:313-318.

20. Human Milk Banking Association of North America. https://www.hmbana.org/.

21. Ewaschuk JB, Unger S, Harvey S, O'Connor DL, Field CJ: Effect of pasteurization on immune components of milk: implications for feeding preterm infants. Appl Physio/ Nutr Metab 2011, 36(2):175-182.

22. Quigley M, Hendersen G, Anthony M, McGuire W: Formula milk versus donor breast milk for feeding preterm or low birth weigh infants. Cochrane Database Syst Rev 2007, 4:CD002971.

23. Sullivan S, Schanler RJ, Kim JH, Patel AL, Trawoger R, Kiechl-Kohlendorfer U, Chan GM, Blanco CL, Abrams S, Cotten M, Laroia N, Ehrenkranz RA, Dudell G, Cristofalo E, Meier P, Lee ML, Rechtman DJ, Lucas A: An exclusively human milk-based diet is associated with a lower rate of enterocolitis than a diet of human milk and bovine milk-based products. J Pediatr 2010, 156:562-567.

24. Donor Milk vs. Formula in Extremely Low Birth Weight (ELBW) Infants trial. http:// clinicaltrials.gov/ct2/show/NCT01534481?term=donor+milk+trial\&rank=1.

25. Donor Milk for Improved Neurodevelopmental Outcomes trial. http://www. controlled-trials.com/isrctn/pf/35317141.

26. Wight NE: Donor human milk for preterm infants. J Perinatol 2001, 21:249-254.

27. Ganapathy V, Hay JW, Kim JH: Costs of necrotizing enterocolitis and cost-effectiveness of exclusively human milk-based products in feeding extremely premature infants. Breastfeed Med 2012, 7(1):29-37.

doi:10.1186/1746-4358-9-4

Cite this article as: Panczuk et al:: Human donor milk for the vulnerable infant: a Canadian perspective. International Breastfeeding Journal 2014 9:4.

\section{Submit your next manuscript to BioMed Central and take full advantage of:}

- Convenient online submission

- Thorough peer review

- No space constraints or color figure charges

- Immediate publication on acceptance

- Inclusion in PubMed, CAS, Scopus and Google Scholar

- Research which is freely available for redistribution

Submit your manuscript at www.biomedcentral.com/submit 